\title{
EXPERIENCE WITH DISODIUM CROMOGLYCATE (INTAL)
}

\author{
Major J. CARSON, M.B., M.R.C.P., D.T.M.\&H., R.A.M.C. \\ Cambridge Military Hospital, Aldershot
}

SUMMARY: A trial of disodium cromoglycate in patients with obstructive airways disease was carried out at the Cambridge Military Hospital, Aldershot from February 1969 to October 1969.

The effects of the drug on selected patients, the assessment of response, and the place of "Intal" in treatment are discussed with particular reference to service practice.

\section{Introduction}

Disodium cromoglycate is a non-toxic drug which is rapidly absorbed from the peripheràl airways, little absorption taking place from the intestinal tract. Rapid elimination in urine and bile follows in a largely unchanged state. It is known to inhibit both immediate and delayed hypersensitivity reactions acting somewhere between antigenantibody union and the release of chemical mediators, but has no intrinsic antiinflammatory or bronchodilator effects. It is therefore used as a prophylactic drug, and is given by frequent inhalation as a dry powder.

\section{Methods}

Nine patients with obstructive airways disease were selected for the trial. Their degree of disability. and the chemotherapy they were receiving remained substantially constant during the three to twelve months prior to entering the trial and no changes other than dose adjustments were made during the trial.

Serial estimations of the forced expiratory volume in one second $\left(\mathrm{FEV}_{1}\right)$ and forced vital capacity (FVC) were recorded at the same time of day in all cases using a dry spirometer (Vitalograph). Chemotherapy and the patients own assessment of well being were noted.

All but one of the patients were skin tested to a range of antigens by the "Prick" method.

\section{Selection and Classification of Patients}

Seven of the patients had bronchial asthma and showed type I skin hyper-sensitivity. They were all therefore "Extrinsic" asthmatics but were divided on clinical grounds into two groups. Two other patients with chronic bronchitis were included in a third group.

Group I consisted of four patients whose asthma began in childhood or adolescence, who had marked variability in the severity of their symptoms, and who recognised specific precipitants for their attacks. These patients had strongly positive skin tests to a wide range of antigens.

Group $I I$ consisted of three patients whose asthma commenced in adult life who showed less variability in severity of symptoms, and who did not recognise specific precipitants for their attacks. This picture suggested "Intrinsic" asthma, but they all showed some positive though weaker reactions to skin testing and were thus examples of extrinsic asthma of low atopic status (Pepys 1967). 
Group III consisted of two army pensioners with chronic bronchitis whose main problem at the time of the trial was obstructive airways disease requiring therapy with steroids and bronchodilators. They both took prompt antibiotic therapy on their own initiative if their sputum changed from mucoid or if they developed upper respiratory tract infection. The younger of them was skin tested with negative results.

\section{Results}

The results in each group are given in Tables I to III respectively.

The initial vitalograph readings are normally the mean of two monthly recordings while the subsequent results are the mean of the last two recordings except when the patient was seen once only.

\section{Discussion}

A simple outline of the chain of events in allergic asthma is shown in Figure 1, together with a suggested site of action of various therapuetic measures. It will be seen that "Intal" may be used in addition to other measures, but may not necessarily replace them.

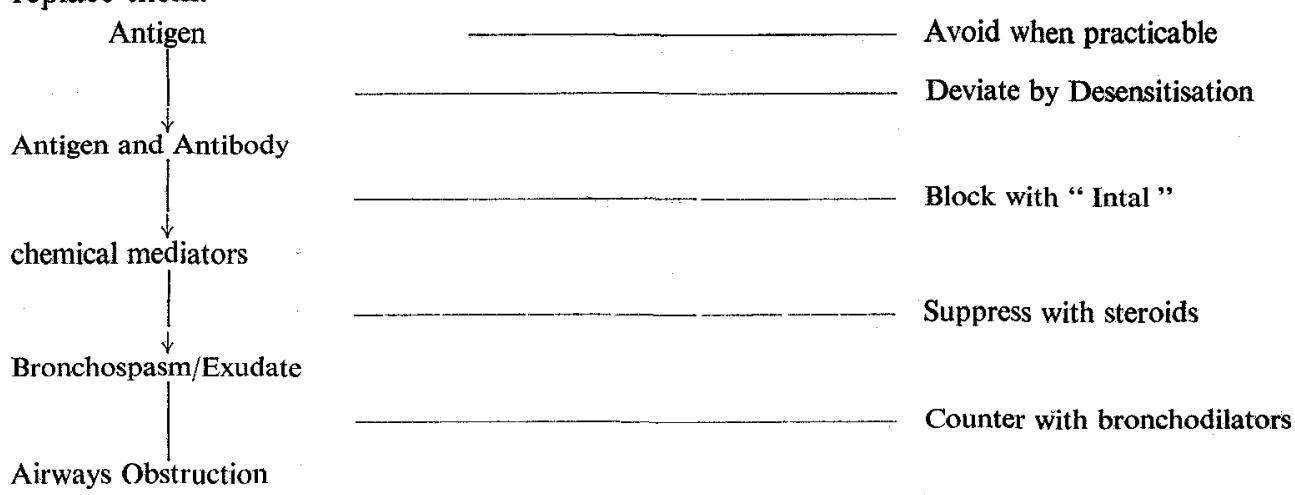

Fig. 1. Outline of chain of events in allergic asthma

The earlier papers describing the clinical value of disodium chromoglycate were favourable (Howell and Altounyan 1967, Kennedy 1967, Moran, Bankier and Boyd 1968 ) and the latter authors reported its special value in " allergic " asthma and observed that the presence of bronchitis was not a contra indication to its use. Morrison, Smith and Devey (1968) reported on the treatment of 44 children with long standing asthma and found over half were better with "Intal", but 30 per cent showed no change.

Less success has been reported by others. Grant, Channell and Drever (1967) were particularly critical while Kidner, Meissner, Pride and Bruce-Pearson (1968) reported improvement in 10 of 28 patients and considered the response in allergic and nonallergic asthma to be similar.

Assessment of response. Kennedy (1967) stated " The most important pre-requisite in evaluating this drug .... is to map out accurately, objectively and subjectively by the pattern of behaviour before treatment". Any assessment however remains difficult in view of the number of variable factors involved.

Allergic status. It has been suggested that young patients with high atopic status would respond best, and although conflicting results have been reported by others, this view is supported in the present series. 
Group II. " Clinical " intrinsic asthma

\begin{tabular}{|c|c|c|c|c|c|c|c|c|c|c|}
\hline \multirow{3}{*}{ Patient } & & & \multicolumn{3}{|c|}{ Initial daily therapy } & \multicolumn{3}{|c|}{ Final daily therapy } & \multicolumn{2}{|c|}{ FEV $1 / F V C$ (Litre) } \\
\hline & \multicolumn{2}{|c|}{ Age } & \multirow{2}{*}{$\begin{array}{l}\text { Steroid } \\
\text { mg }\end{array}$} & \multicolumn{2}{|c|}{ Bronchodilator } & \multirow{2}{*}{$\begin{array}{c}\text { Steroid } \\
\text { mg }\end{array}$} & \multicolumn{2}{|c|}{ Bronchodilator } & \multirow{2}{*}{ Initial } & \multirow{2}{*}{ Final } \\
\hline & Present & Onset & & Oral & Inhaled & & Oral & Inhaled & & \\
\hline Cpl R & 37 & 32 & 20 & 6 & 6 & 15 & 6 & 0 & $\begin{array}{l}2.2 \\
4.3\end{array}$ & $\begin{array}{l}2.15 \\
4.0\end{array}$ \\
\hline Sgt W & 36 & 24 & 30 & 3 & 3 & 25 & 3 & 3 & $\begin{array}{l}1.05 \\
2.15\end{array}$ & $\begin{array}{l}1.75 \\
3.6\end{array}$ \\
\hline Q Sgt B & 47 & 37 & 0 & 3 & 2 & 0 & 3 & 0 & $\begin{array}{l}1.7 \\
2.5\end{array}$ & $\begin{array}{l}1.8 \\
2.5\end{array}$ \\
\hline
\end{tabular}

Table III

Group III. Chronic bronchitis

\begin{tabular}{|c|c|c|c|c|c|c|c|c|c|c|c|c|}
\hline \multirow{3}{*}{ Patient } & & & \multicolumn{3}{|c|}{ Initial daily therapy } & \multicolumn{3}{|c|}{ Final daily therapy } & \multicolumn{2}{|c|}{ FEV1/FVC (Litre) } & \multirow{3}{*}{$\begin{array}{c}\begin{array}{c}\text { Peried } \\
\text { of } \\
\text { reviedv }\end{array} \\
\underset{\text { In }}{\text { In }} \\
\text { months }\end{array}$} & \multirow{3}{*}{ Comment } \\
\hline & \multicolumn{2}{|c|}{ Age } & \multirow{2}{*}{$\begin{array}{l}\text { Steroid } \\
\text { mg }\end{array}$} & \multicolumn{2}{|c|}{ Bronchodilator } & \multirow{2}{*}{$\begin{array}{c}\text { Steroid } \\
\text { mg }\end{array}$} & \multicolumn{2}{|c|}{ Bronchodilator } & \multirow{2}{*}{ Initial } & \multirow{2}{*}{ Final } & & \\
\hline & Present & Onset & & Oral & Inhaled & & Oral & Inhaled & & & & \\
\hline Mr. S & 49 & 38 & 10 & 2 & 3 & 6 & 0 & 1 & $\begin{array}{l}1.9 \\
2.8\end{array}$ & $\begin{array}{l}1.85 \\
3.2\end{array}$ & 焉 & No subjective benefit \\
\hline Mr. C & 60 & 30 & 5 & 3 & 6 & 5 & 2 & 2 & $\begin{array}{l}0.3 \\
0.8\end{array}$ & $\begin{array}{l}0.3 \\
0.8\end{array}$ & $\begin{array}{l}\text { NO } \\
\text { No }\end{array}$ & Subjectively slightly better \\
\hline & & & & & & & & & & & 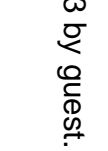 & \\
\hline
\end{tabular}

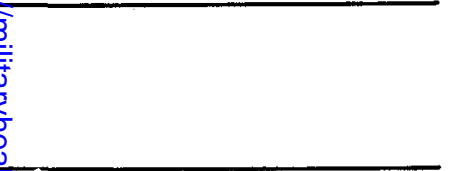


Seasonal variation. Patients with high pollen sensitivity are likely to show variations in symptoms with changes in pollen count, which in turn vary with weather conditions. One patient (S/O Capt. B) had predominantly summer asthma with high sensitivity to grass pollen and his improvement during the summer was considered significant.

Chronic bronchitis Although it has been noted that bronchitis does not preclude "Intal" therapy its use in such patients must be considered critically. The distinction between asthma of late onset and mild chronic bronchitis may be difficult especially with men in the fourth decade referred with dyspnoea and wheeze on exertion.

All but the two youngest patients in the series smoked cigarettes, and those in Group II had regularly smoked over 20 cigarettes daily in the recent past. The latter group all had productive cough, and despite temporary reversibility of airways obstruction with isoprenaline, they had more persistent wheeze and showed only doubtful or marginal benefit from " Intal".

The two patients with chronic bronchitis showed no appreciable benefit.

Time of day. All measurements of $\mathrm{FEV}_{1}$ and FVC were made at the same time of day and are therefore comparable, although it is appreciated that the timing of estimations is not necessarily ideal in assessing the individual patient (Robertson, Epstein and Warrel 1969).

Concurrent therapy. Five of the asthmatic patients were receiving concurrent steroid therapy and all were taking some form of bronchodilator therapy. The large proportion of patients on steroids and the large doses given to two patients in Group II reflect the selection of more affected patients.

The reduction in dosage of steroids achieved with "Intal" therapy is of special importance in the young, whose growth may be affected, and in all age groups by reducing the risk of side effects. Kennedy (1967) and Morrison-Smith and Devey (1968) have commented upon the advantages of reducing steroid dosage, but this must be done with care as "Intal" has no steroid like effects.

Objective and Subjective Assessment. In a condition in which airways obstruction is of considerable importance serial tests of ventilatory function might be thought satisfactory to assess progress, but unfortunately this is not so. Hughes (1969) in discussing pulmonary function tests observed that subjective benefit from therapy is not always reflected in routine spirometry. In particular the $F_{E V}$ may remain constant while the vital capacity and peak flow rate (PFR) are increasing. Similar discrepancies had previously been observed during trials with steroid therapy by Woolcock and Read (1965) who commented upon the reduction in capacity of the hyperinflated lung accompanied by subjective improvement, but an unchanged $\mathrm{FEV}_{1}$.

Measurements of FEV 1 and PFR are possible in all military hospitals, although more sophisticated investigations are not available. One may well ask however if it is not sufficient to accept the patients' own opinion as to whether or not improvement has occurred. This is satisfactory when the result is dramatic as in the case of Cpl. J., or when there is collateral evidence as with S/O WOI. T. whose schoolteacher commented upon his improved performance.

The main objection to accepting a purely subjective assessment is the "Placebo" effect (Beecher 1955), and it is now recognised that an inert placebo will exert a beneficial 
effect on a considerable proportion of recipients. Intal has a distinctive taste, and a certain ritual is attached to its use making a "Placebo" effect likely. Nevertheless the improvement noted in patients in Group $I$ in particular was felt to be of pharmacological origin.

Selection of Patients. The majority of individuals with bronchial asthma are not suitable for military service and should be rejected or invalided. As a result, young patients with a high degree of allergy who are ideally suited for "Intal " therapy will not be seen in service practice.

Greater difficulty arises with trained soldiers who develop asthma in adult life. Some may have intrinsic asthma, but a more vigorous search for allergens will show an increasing proportion to have extrinsic asthma of low atopic status (Pepys 1967).

In this series no patient in Group II was able to recognise a specific inhalant or ingestant which precipitated asthma, and in the absence of skin testing would have been classified as intrinsic asthma. The classification of "Clinical intrinsic asthma" adopted for this group appears to be of some practical value, since these patients do less well on Intal as indeed is the case with other therapeutic agents.

It has already been noted that the patients in Group II probably had early chronic bronchitis which would mitigate against improvement on Intal. The two patients with frank chronic bronchitis obtained no benefit from the drug even after prolonged therapy in one case.

\section{Conclusion}

Disodium cromoglycate has a limited application in service practice. It is ideally suited to the young asthmatic with high atopic status. Such patients may be seen by families medical officers, but recruits and potential recruits in this category will be rejected.

Servicemen or their families presenting with asthma of late onset are a more difficult problem. They may present a picture of "Clinical intrinsic asthma" and an element of chronic bronchitis may co-exist. Their symptoms tend to be persistent and resistant to usual forms of treatment. Unfortunately these patients tend to show a poor response to "Intal ". It is therefore most important that the use of this drug is assessed critically in every case, and continued only if definite improvement is obtained.

The drug appears to have no place in the treatment of patients with chronic bronchitis.

\section{Acknowledgement}

I would like to thank Colonel J. F. Webb, M.C., Late R.A.M.C. for advice in the preparation of this paper.

\section{REFERENCES}

BEECHER, H. K. (1955). J. Amer. med. Ass. 159, 1602.

Grant, I. W. B., ChanNel, S. and DReVer, J. C. (1967). Lancet ii, 673.

Howell, J. B. L. and Altounyan, R. E. C. (1967). Lancet ii, 539.

Hughes, D. T. D. (1969). Brit. med. J. iv, 356.

Kidner, P. H., Meisner, P., Pride, N. B. and Brude-Prarson, R. S. (1968). Lancet ii, 656.

Moran, F., BANKIER, J. D. H. and BoYd, G. (1968). Lancet ii, 137.

Morrison-SMith, J. M. and DeVeY, G. F. (1968). Brit. med. J. ii, 340.

PePYS, J. (1967). J. roy. Colls. Phycns Lond. ii, 42.

READ, J. and WoolCOCK, A. J. (1965). Lancet ii, 1323.

Robertson, D. G., EpsteIn, S. W. and WARRell, D. A. (1969). Brit. med. J, i, 552. 